\title{
Long-Term Retardation of Water Evaporation by Ultra-Thin Layers of Polydimethylsiloxanes in the Indoor Conditions
}

\author{
Volodymyr Zhuk ${ }^{1 *}$, Andriy Rehush², Sofiya Burchenya², Oleh Hrytsiv³ \\ 1 Institute of Civil Engineering and Building Systems, Lviv Polytechnic National University, Karpinsky Str. 6, Lviv, \\ Ukraine \\ 2 Faculty of Building and Architecture, Lviv National Agrarian University, V. Velykyi Str. 1, Dubliany, Lviv region, \\ Ukraine \\ ${ }^{3}$ Galio Ltd, Antonych Str. 20v, Lviv, Ukraine \\ * Corresponding author's e-mail: volodymyr.m.zhuk@lpnu.ua
}

\begin{abstract}
Global climate change is causing water imbalances in many regions of the world to exceed evaporation over rainfall, leading to negative environmental consequences and economic losses. An effective way to reduce the water loss due to evaporation from the free surface of water bodies is the use of ultra-thin surface films of special additives. Insufficient stability and significant cost of additives based on fatty alcohols (hexadecanol, octadecanol and their mixtures) necessitate searching for new effective and more economical additives to reduce the water loss due to evaporation. A series of long-term (84 day) experimental studies of the effect of ultra-thin layers of polydimethylsiloxanes PDMS100 and PDMS-200 with a thickness of $1 \mu \mathrm{m}$ on the rate of evaporation of water from the free surface was conducted under the indoor laboratory conditions. Both the dynamics of change in time of daily values of the effect of evaporation retardation by PDMS films, and total effect from the beginning of experiment were obtained. The maximum daily effects of evaporation retardation were obtained on the 6th day of the study; they are $39.5 \%$ for the PDMS-200 film and $32.9 \%$ for the PDMS-100 film, respectively. Linear correlations are obtained between the values of the mass transfer coefficient and the free surface temperature for water without additives, as well as for the same free surfaces with ultra-thin PDMS films. Overall integral efficiency of evaporation retardation by the PDMS-200 film with a thickness of $1 \mu \mathrm{m}$ for 84 days was equal to $17.2 \%$, while for the PDMS-100 film of the same thickness a reduction of evaporation by $5.7 \%$ was obtained. Due to the long-term activity, ultra-thin films of polydimethylsiloxanes, especially PDMS-200, can be a profitable alternative to the use of monolayers based on fatty alcohols.
\end{abstract}

Keywords: evaporation retardation, mass-exchange coefficient, monolayer, polydimethylsiloxane, ultra-thin layer, water balance.

\section{INTRODUCTION}

The tendency of increasing the average annual temperature causes a significant violation of the water balance of territories and water bodies as a result of a significant increase in water losses due to evaporation. According to the estimates of [Information and Analytical Report, 2020] under Ukrainian climate conditions, the growth of the average monthly temperature by $1{ }^{\circ} \mathrm{C}$ causes an increase in total evaporation by about $9 \%$. Thus, the total water evaporation from the territory of
Ukraine in 2020 was $40-45 \mathrm{~km}^{3}$ per year higher comparing with the corresponding value in 1990, which translates into an average growth of $1.7-1.9 \%$ annually. In many regions of the world, the evaporation layer significantly exceeds the depth of the precipitation layer. Compared to Ukraine, where the intensity of evaporation from water bodies in summer is in the range of 1-4 $\mathrm{mm}$ /day [Rudakov et al., 2017], in countries with hot and dry climates, this value reaches $8-10$ $\mathrm{mm}$ /day and more [Gorjizade et al., 2014; Saggaï $\&$ Bachi, 2015; Shilo et al., 2015]. Therefore, the 
problems of increasing water losses due to evaporation, estimation of evaporation intensity and its impact on water balances are the subject of extensive scientific analyses [Chigrinets et al., 2019; Weiss et al., 2019; Zhuk et al., 2021].

In recent decades, there has been an active search for the ways to reduce the water losses from the water body's surface due to the evaporation. Among modern engineering practices, the most common methods of reducing evaporation are floating protective coatings, suspended coatings, modular coatings, ultra-thin protective films of special liquids and the addition of polyacrylamide [Craig et al., 2005; Liu et al., 2011].

The use of special macromolecular additives has shown special prospects. Such additives form on the water surface ultra-thin films with a thickness of one to several molecular layers (monolayers), which can significantly increase the resistance to evaporation of water. This method of reducing water losses due to evaporation has been actively studied and implemented in the driest regions of the world in recent decades. An active study of the effect of monolayers on the rate of water evaporation from the free surface of water bodies began in the 1950s in the United States and Australia. In 1960, a specialized symposium of the American Chemical Society was held, which resulted in the publication of a monograph [Retardation of Evaporation by Monolayers: Transport Processes, 1962] that presented the most important results on the impact of monolayers on water evaporation.

Today, the most studied additives of this type are fatty alcohols: cetyl alcohol (hexadecanol, $\mathrm{C}_{16} \mathrm{H}_{33} \mathrm{OH}$ ), stearyl alcohol (octadecanol, $\mathrm{C}_{18} \mathrm{H}_{37} \mathrm{OH}$ ) and their mixtures, which reduce the water loss by evaporation by an average of 20-30\%, in some cases - up to 50-60\% [Gugliotti et al., 2005; Panjabi et al., 2016; Saggaï and Bachi, 2018]. The effect of evaporation retardation depends on the type of additive and film thickness, as well as on the method of film formation and environmental conditions (water and air temperature, relative humidity, solar radiation intensity, wind speed, dust, etc.) [Gallego-Elvira et al., 2013].

From the ecological point of view, a number of advantages of application of such monolayers were noted: fatty alcohols have no smell and color, do not worsen the penetration of solar radiation into the water bodies and practically do not influence the content of dissolved oxygen in water. Monolayers also restrain the formation of water waves, slightly increase the temperature and reduce the coefficient of surface tension of the water surface. An important practical disadvantage of fatty alcohols as additives to reduce the evaporation losses is their relatively high cost and low stability, which reduces the technical and economic efficiency of using the protective films of fatty alcohols. In recent decades, there has been an active search for new, effective and inexpensive additives that are able to form especially thin protective films on the surface of water that reduce the water loss due to evaporation [Bukhari et al., 2011; Zhuk et al., 2020].

Of particular interest in this direction are polydimethylsiloxanes (PDMS) or silicone oils - polymerized siloxanes, organosilicon liquids, which have a number of advantages over fatty alcohols and are widely used in practice: in the food industry, cosmetology and pharmaceuticals, as lubricants and protective coatings for metal structures etc. [Eduok et al., 2017; Mojsiewicz-Pieńkowska, 2015].

The analysis of the results of sanitary and toxicological studies shows that the PDMS- 100 and PDMS-200 polydimethylsiloxanes are environmentally friendly and non-toxic for both humans and aquabiots. PDMS-100 is used in the food industry as a defoamer, it is known as a food additive E900, and is completely safe for the human body. Polydimethylsiloxanes do not cause irritation or allergies, are not absorbed by organisms and are excreted through the gastrointestinal tract [Mojsiewicz-Pieńkowska, 2015]. An illustrative example of the safety of PDMS is their use in pharmacy, medicine and cosmetology; for example, in the international nomenclature of cosmetic substances PDMS-200 is classified under the number CAS 63148-62-9. In medicine, PDMS are used under the name dimethicone and simethicone. These drugs relieve pain in the intestines; they are not absorbed into the blood. The Polish National Institute of Health has established that if dimethicone and simethicone are taken as prescribed, they have no side effects [Mojsiewicz-Pieńkowska, 2015].

The components of the silicone coating are better resistant to ultraviolet degradation compared to, for example, polyurethane coatings [Eduok et al., 2017]. Due to almost complete insolubility in water and due to the high adsorption properties, the PDMS used in water bodies are effectively adsorbed on suspended particles, which settle to the bottom. PDMS are effectively 
removed in sewage treatment process at wastewater treatment plants (WWTP); the analysis of the PDMS content in the treated effluents at eight WWTP, presented in [Fendinger et al., 1997], showed that in most samples the content of PDMS was below the sensitivity limit (5 $\mu \mathrm{g} / \mathrm{L}$ ), while in dewatered sludge, the content of PDMS was within from 290 to $5155 \mathrm{mg} / \mathrm{kg}$, depending the influent concentration of PDMS and sludge processing method.

Degradation of PDMS occurs in soils of different types. The primary product of the PDMS hydrolysis is dimethylsilanediol, which is either biodegradable or evaporates into the atmosphere, where it is subsequently oxidized under the action of sunlight. The end products of decomposition in both cases are completely environmentally safe compounds: $\mathrm{SiO}_{2}, \mathrm{CO}_{2}$ and $\mathrm{H}_{2} \mathrm{O}$ [Graiver et al., 2003]. In wet soils, decomposition of silicones is slow enough (only $3 \%$ for 6 months); however, in the same soils, but in the dry state, their decomposition is very fast $-50 \%$ in a few days [Griessbach \& Lehmann, 1999].

Field studies in rice paddies in Kenya have shown a positive effect from the use of PDMS films to control malaria mosquitoes. It was found that after the application of $2 \mathrm{ml} / \mathrm{m}^{2}$ of PDMS based solution on rice paddies, the number of mosquito larvae of the early stage decreased by $36 \%$, and of the late stage mosquito larvae by $16 \%$. The mechanism of action of monomolecular films is explained by the blockage of the respiratory tract of malaria mosquitoes. It was found that PDMS does not adversely affect the rice crop and has significant potential for use under the climatic conditions of Kenya and the region [Bukhari et al., 2011].

\section{MATERIALS AND METHODS}

The quantitative indicators of the process of water evaporation were investigated on the basis of ultra-thin films of the PDMS-100 and PDMS-200 polydimethylsiloxanes. In order to find the effect of ultra-thin films of PDMS-100 and PDMS-200 with a thickness of $1 \mu \mathrm{m}$ on the rate of water evaporation a series of long-term experimental studies was performed under the laboratory conditions.

The process of water evaporation from three identical rectangular tanks with dimensions $42 \times 27 \mathrm{~cm}$ was subject of research. In the tank \#1 the water surface was covered with ultra-thin film of PDMS-100 with a thickness of
$1 \mu \mathrm{m}$, in the tank \#2 - the same film of PDMS200 , the control tank \#0 was filled with clean tap water without any additives.

The mass of evaporated water, the rate and intensity of evaporation were determined by using the volumetric method, measuring daily the residual mass of tanks with liquid using an electronic scale AXIS BDU-60 with a maximum absolute error of $\pm 0.01 \mathrm{~kg}$. Simultaneously, temperature and relative humidity of the air in the laboratory were measured. The air temperature - by dry bulb thermometer $\left(\mathrm{T}_{\mathrm{d} . \mathrm{b}}\right)$ and a wet bulb thermometer $\left(\mathrm{T}_{\mathrm{w} . \mathrm{b}}\right)$ was measured using standard laboratory hygrometers VIT-1 and VIT-2. Using the values of $T_{\text {d.b }}$ and $\mathrm{T}_{\text {w.b }}$ relative humidity $\mathrm{RH}$ was calculated. The investigation was fulfilled under the indoor laboratory conditions, without direct access to sunlight, with minimal intensity of ultraviolet radiation, without forced air movement over the lab tanks.

The daily effect (or current efficiency) of the PDMS-100 and PDMS-200 films in the day $t$ was defined as the relative reduction of evaporation water losses in tanks with PDMS films compared to the same tank with water without any additives:

$$
E_{i . t}=\frac{\Delta M_{i . t}-\Delta M_{0 . t}}{\Delta M_{0 . t}} \times 100 \%
$$

where: $\Delta M_{i . t}-$ water losses due to evaporation in tanks with the PDMS $1 \mu \mathrm{m}$ film, per $\mathrm{t}$-th day ( $\mathrm{i}=1$ for PDMS-100; $\mathrm{i}=2$ for PDMS-200); $\Delta M_{0 . t}-$ water loss due to evaporation from the tank without any additives, per t-th day.

The total effect (or integral efficiency) of PDMS films was defined as the relative reduction of evaporation water losses in the tanks with PDMS films compared to the control tank with clean water, from the beginning of the series to the control date:

$$
E_{i . t o t}=\frac{\Delta M_{i . t o t}-\Delta M_{0 . t o t}}{\Delta M_{0 . t o t}} \times 100 \%
$$

where: $\Delta M_{\text {i.tot }}$ - total water losses due to evaporation in tanks with PDMS $1 \mu \mathrm{m}$ films for the first $t$ days of the experiment $(i=1$ for PDMS-100; $i=2$ for PDMS-200); $\Delta M_{\text {o.tot }}$ - total water loss on evaporation from the tank with clean tap water for the first $t$ days of the experiment.

The mass transfer coefficient $\beta_{\mathrm{p}}$, s/m, was found from the convective mass transfer equation: 


$$
\beta_{p}=\frac{m}{\left(p_{F}-p_{a}\right)}
$$

where: $m$ is the mass flow density, $\mathrm{kg} /\left(\mathrm{s} \times \mathrm{m}^{2}\right) ; p_{F}$, $p_{a}$ - partial pressure of water vapor, respectively, near the free surface of water and in the air, $\mathrm{Pa}$.

When finding the water vapor partial pressure on the free surface, it was assumed that the temperature of the diffusion boundary layer is equal to the air temperature by the wet bulb thermometer, and the relative humidity is $100 \%$; Partial pressure of water vapor in the air was found according to the standard method, based on the pressure of saturated water vapor at temperature $\mathrm{T}_{\mathrm{d} . \mathrm{b}}$ and on the relative humidity $\mathrm{RH}$.

\section{RESULTS AND DISCUSSION}

As a result of long-term investigation of water evaporation under laboratory conditions, the time dependences of the main parameters characterizing the reduction of the evaporation rate by means of the PDMS-100 and PDMS-200 ultra-thin films with a thickness of $1 \mu \mathrm{m}$ were obtained.

The change in environmental conditions during a series of experimental studies with a total duration of 84 days is shown in Figure 1. Air temperature dry bulb thermometer $\mathrm{T}_{\text {d.b }}$ was in the range from $13.3^{\circ} \mathrm{C}$ to $18.5^{\circ} \mathrm{C}$ with weighted mean value of $\mathrm{T}_{\text {d.b.mid }}=15.2^{\circ} \mathrm{C}$; the corresponding air temperature by the wet thermometer $\mathrm{T}_{\mathrm{w} . \mathrm{b}}$ varied in the range of $12.2-17.2{ }^{\circ} \mathrm{C}$ with weighted mean value of $\mathrm{T}_{\text {w.b.mid }}=13.5^{\circ} \mathrm{C}$.

The temperature of water $\mathrm{T}_{\mathrm{W}}$ was usually slightly higher than the air temperature by the dry bulb thermometer, but significantly lower than the temperature by the dry bulb thermometer, varying during the experiment from $12.1{ }^{\circ} \mathrm{C}$ to $17.0^{\circ} \mathrm{C}$ with a time-average value of $\mathrm{T}_{\mathrm{W} \text { mid }}=13.9^{\circ} \mathrm{C}$. Throughout the series, the relative humidity in the laboratory was high, varying in the range from $71.5 \%$ to $91.2 \%$ with an average value of $\mathrm{RH}_{\text {mid }}=81.7 \%$.

The graphs of changes in time of the daily effect of reducing water evaporation using the PDMS-100 and PDMS-200 ultra-thin films with a thickness of $1 \mu \mathrm{m}$ are presented in Figure 2. It was obtained that the daily efficiency of reducing evaporation with PDMS-200 film significantly exceeded the corresponding values for the PDMS-100 film; this is especially evident during the second half of the study, starting from 39 day until the end of the series. The maximum daily effect of the PDMS-200 film is $39.5 \%$ and was observed on the 6 th day of the experiment. On the same day, the maximum daily effect was also obtained from the PDMS-100 film $-32.9 \%$. In the period from 13 th to 18 th day, the efficiency of PDMS-100 was significantly higher comparing with PDMS-200, reaching the second maximum of $31.8 \%$ on the 15 th day. At the 36 th day from the start of experiment, the minimum daily effects for both films were obtained, namely $-11.1 \%$ for PDMS-100 and -9.4\% for PDMS-200. It seemed like cessation of films' activity, but from

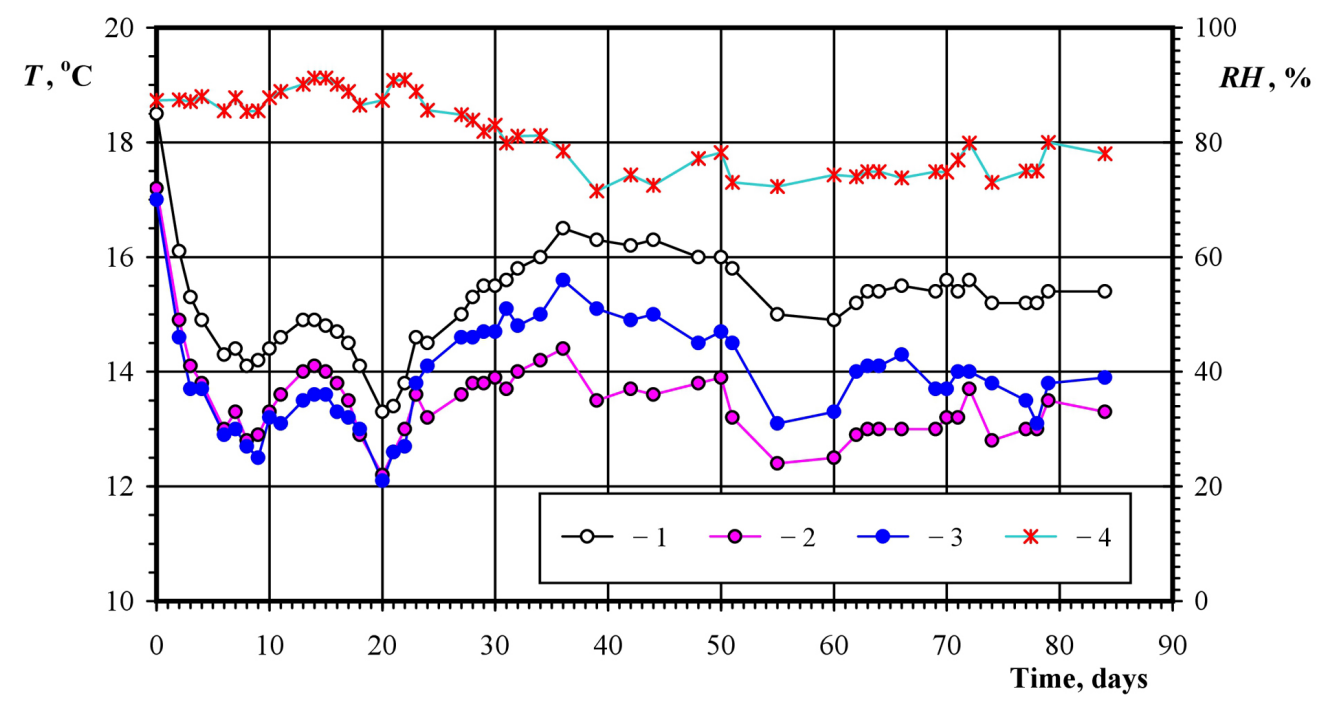

Figure 1. Change of environmental parameters during the experimental study of the effect of PDMS ultra-thin films on the intensity of water evaporation under the laboratory conditions: 1, 2- air temperature, respectively, by dry thermometer $\mathrm{T}_{\text {d.b }}$ and by wet bulb thermometer $\mathrm{T}_{\mathrm{w} . \mathrm{b}} ; 3$ - water temperature $\mathrm{T}_{\mathrm{w}} ; 4$ - relative humidity $\mathrm{RH}$ 
39th day, the retardation of evaporation in tanks with PDMS films was steadily restored, but at significantly different levels of efficiency. Thus, in the tank with the PDMS-100 film, the daily efficiency did not exceeded $10.5 \%$, while the effect of PDMS200 film varied during this period in the range of $6.4 \%$ in 44 th day up to $30.9 \%$ in 78 th day.

More stable and smooth trends are obtained for time trend of the integral effect of reducing water evaporation using ultra-thin PDMS films, taking into account the total reducing of the mass of water that has evaporated since the beginning of the series (Fig. 3). The maximum of the integral efficiency of the PDMS-200 film is equal to $28.4 \%$ and corresponds to the first 7 days of experiment. For the PDMS-100 film, the maximum overall efficiency corresponds to the first 9 days of the series and is equal to $23.3 \%$. From 18th to 36 th day from the start, the overall effect of both PDMS films was very close, with a slight, at most $1.4 \%$, predominance of the PDMS-200 film. After 36th day and until the end of series, the difference between the total effects of the PDMS-200 and PDMS-100 films was constantly increasing. At the end of the series, on the 84th day from the beginning of the study, the overall total effect of evaporation retardation by the PDMS-200 film with a thickness of $1 \mu \mathrm{m}$ was equal to $E_{\text {tot.2f }}=17.2 \%$, while for the PDMS-100 film of the same thickness, the corresponding value is equal to $\mathrm{E}_{\text {totlf }}=5.7 \%$.

Thus, under the same environmental conditions, the long-term overall efficiency of evaporation retardation by $1 \mu \mathrm{m}$ PDMS-200 film is 3.02 times higher than the efficiency of the same PDMS-100

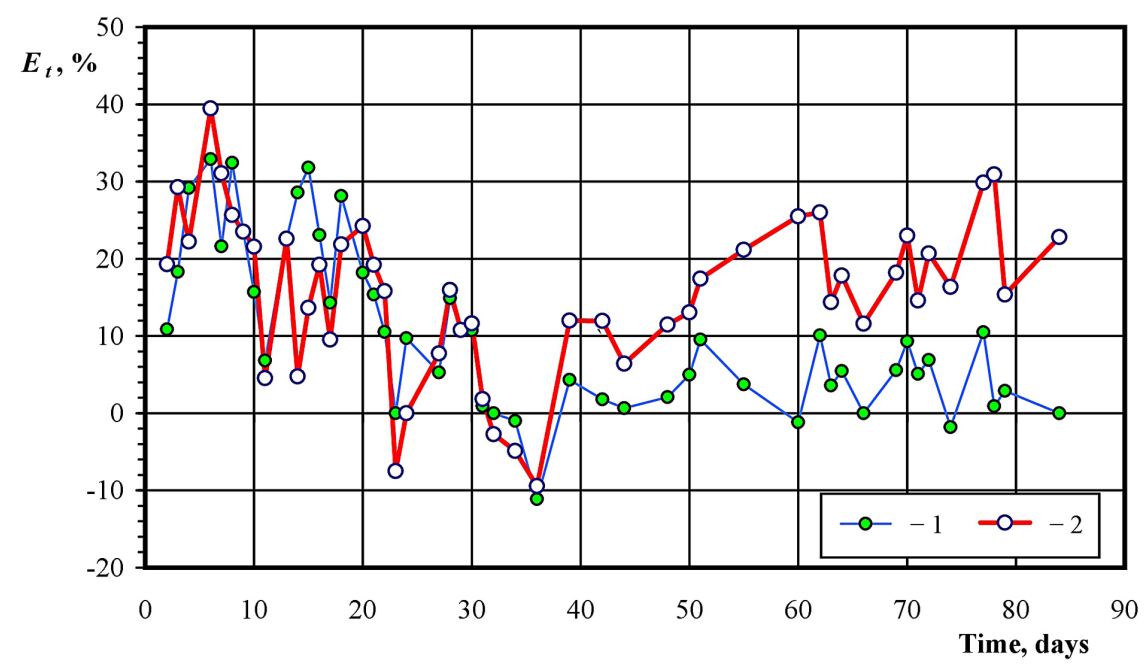

Figure 2. Change in time of the daily effect of water evaporation retardation under the laboratory conditions using ultra-thin films of PDMS with a thickness of $1 \mu \mathrm{m}$ : 1 - PDMS-100; 2 - PDMS-200

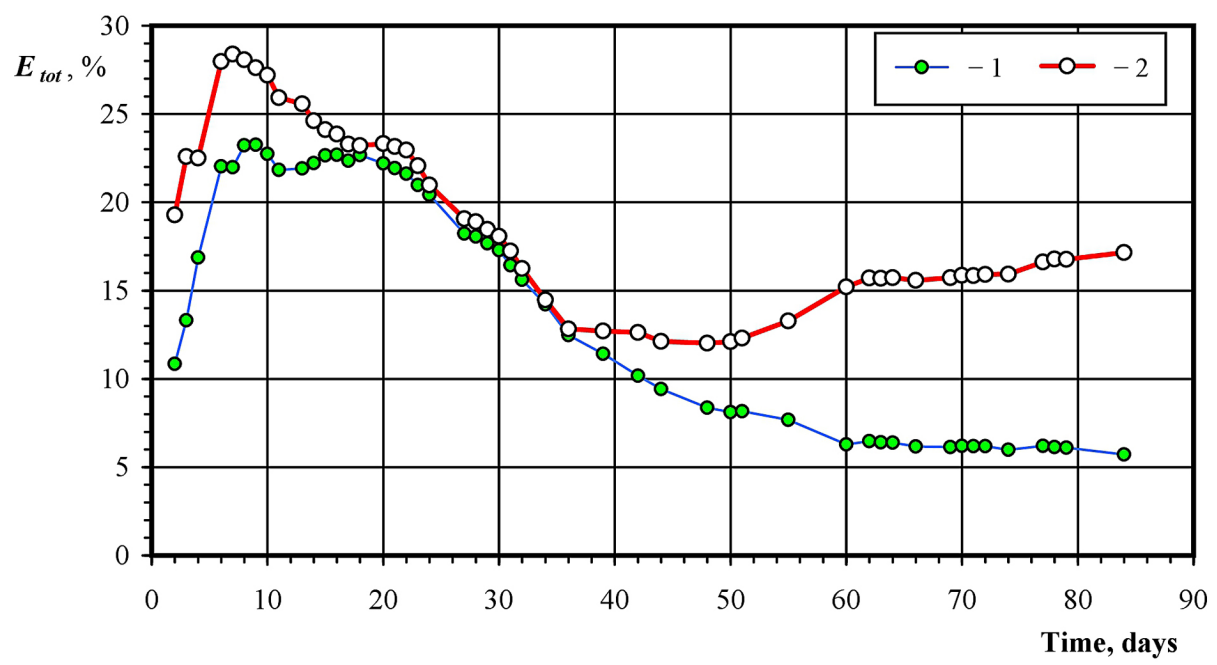

Figure 3. Time dependencies of the total effect of water evaporation retardation using ultrathin films of PDMS with a thickness of $1 \mu \mathrm{m}: 1$ - PDMS-100; 2 - PDMS-200 
film, which is especially important in technical and economic comparison of using different types of PDMS to reduce the evaporation water losses. The total reduction in the evaporation water losses is proportional to the product of the overall efficiency over the duration of the protective action of the film. Thus, considering the long-term efficiency, from an economic point of view, ultra-thin films of polydimethylsiloxanes, especially PDMS-200, can be a profitable alternative to the use of monolayers based on fatty alcohols. As a rule, the period of evaporation retardation by means of films of fatty alcohols does not exceed 7 days that is 12 times less, than the observed time of effective action of a PDMS-200 film that will allow reducing the frequency of introduction of the PDMS additives during long dry periods. On the other hand, when using films to reduce the evaporation water losses during short (about 1 week) dry weather periods, the total efficiency of $1 \mu \mathrm{m}$ PDMS-200 film for the corresponding period is about $28.4 \%$, which is close to the best results for fatty alcohol films.

The correlations between the mass transfer coefficient $\beta_{p}$ and water surface temperature $T_{F}$ for the tank with clean water, as well as for tanks with ultra-thin $1 \mu \mathrm{m}$ films of PDMS-100 and PDMS-200 are shown in Figures 4-6.

Linear approximations (4) - (6) for the mass transfer coefficient $\beta_{\mathrm{p}}, \mathrm{s} / \mathrm{m}$, on the surface temperature $\mathrm{T}_{\mathrm{F}},{ }^{\circ} \mathrm{C}$, are obtained for the temperature range from $12^{\circ} \mathrm{C}$ to $15^{\circ} \mathrm{C}$. For the control tank $\# 0$ with clean water, without additives:

$$
\beta_{p .0}=\left(7.51+0.0079 T_{F}\right) \times 10^{-8}
$$

for tank\#1 with $1 \mu \mathrm{m}$ thickness film of PDMS-100:

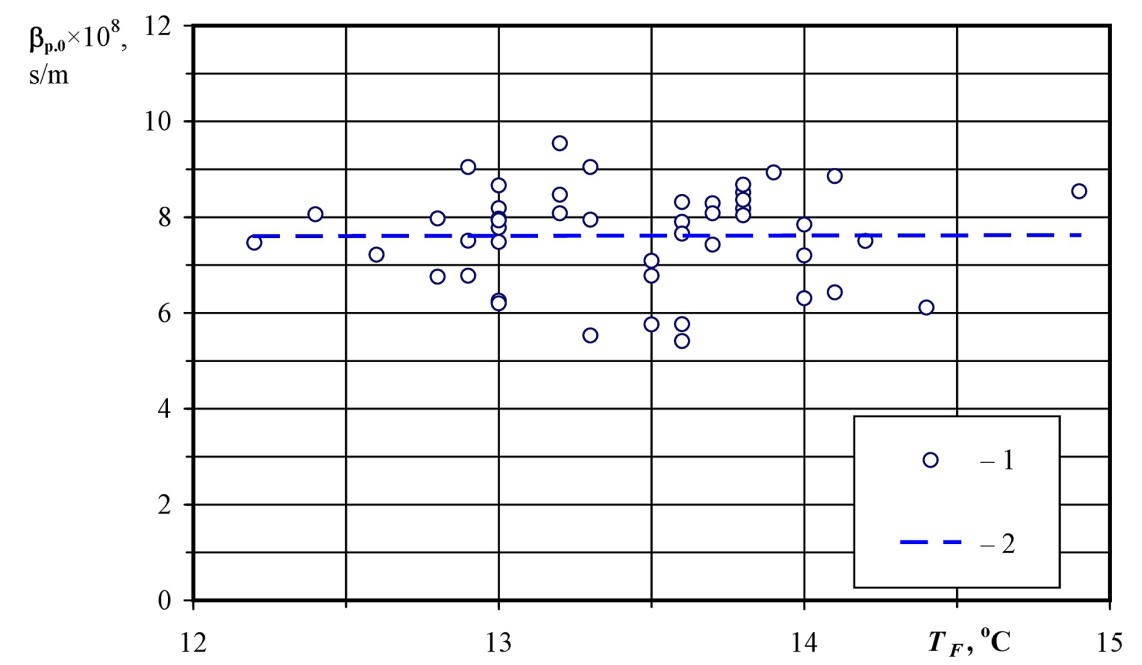

Figure 4. Dependence of the mass transfer coefficient $\beta_{p}$ on the water surface temperature $T_{F}$ for the tank with clean tap water without additives: 1 - experimental results; 2 - linear approximation (4)

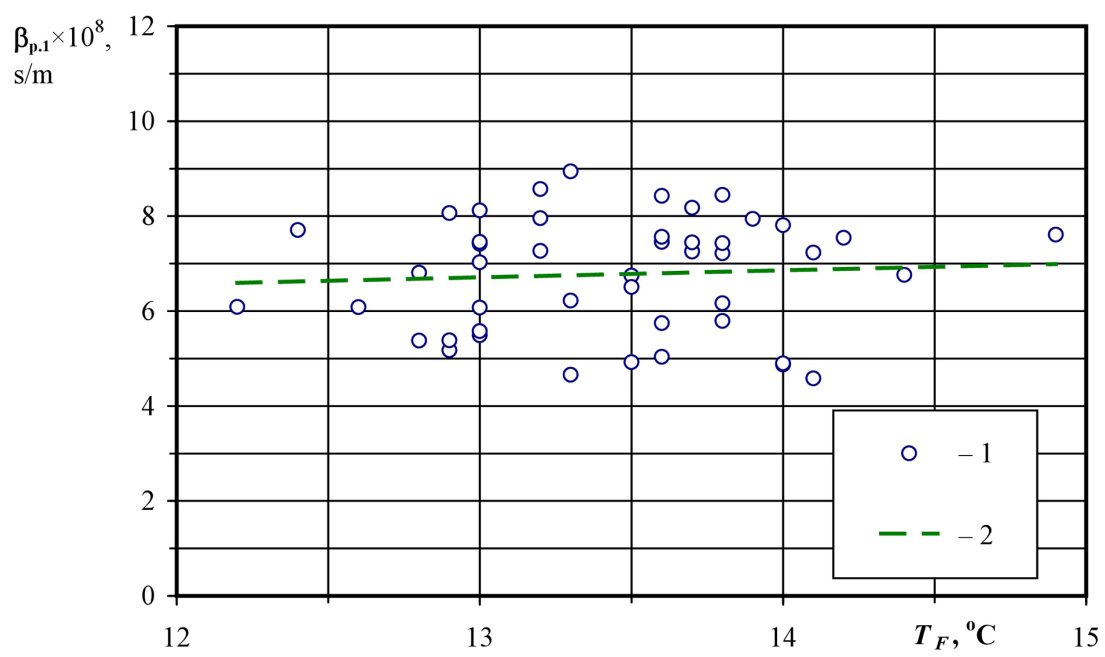

Figure 5. Dependence of the mass transfer coefficient $\beta_{\mathrm{p}}$ on the water surface temperature $\mathrm{T}_{\mathrm{F}}$ for the tank with $1 \mu \mathrm{m}$ film of PDMS-100: 1 - experimental results; 2 - linear approximation (5) 


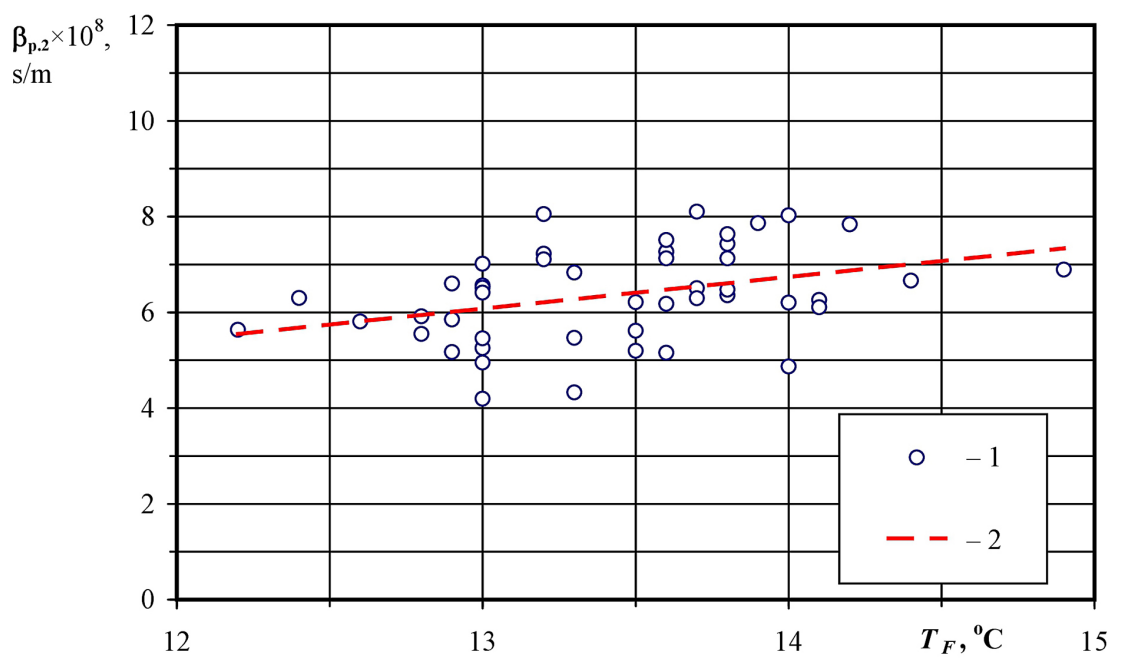

Figure 6. Dependence of the mass transfer coefficient $\beta_{\mathrm{p}}$ on the water surface temperature $\mathrm{T}_{\mathrm{F}}$ for the tank with $1 \mu \mathrm{m}$ film of PDMS-200: 1 - experimental results; 2 - linear approximation (6)

$$
\beta_{p .1}=\left(4.80+0.147 T_{F}\right) \times 10^{-8}
$$

for tank\#2 with ultra-thin $1 \mu \mathrm{m}$ film of PDMS-200:

$$
\beta_{p .2}=\left(-2.58+0.667 T_{F}\right) \times 10^{-8}
$$

\section{CONCLUSIONS}

Global climate change is causing water imbalances in many regions of the world to exceed evaporation over rainfall, leading to negative environmental consequences and economic losses. An effective way to reduce the water loss due to evaporation from the free surface of water bodies is the application of ultra-thin films of special additives. Insufficiently high stability and significant cost of additives based on fatty alcohols (hexadecanol, octadecanol and their mixtures) necessitate searching for new effective and more economical additives to reduce the water loss due to evaporation.

The analysis has shown that a promising way to reduce the water losses due to evaporation from the free surface of water bodies is the application of protective films with PDMS. PDMS-100 and PDMS-200 are widely used in practice, in particular in the food industry, cosmetology and pharmaceuticals, are environmentally safe and non-toxic for both humans and aquabiots; they are effectively adsorbed on suspended particles, concentrating in sediment or in sludge. Degradation of PDMS occurs in soils of different types, and the abiotic path of their decomposition to the simplest ecologically safe compounds $\left(\mathrm{SiO}_{2}, \mathrm{CO}_{2}\right.$ and $\left.\mathrm{H}_{2} \mathrm{O}\right)$ prevails. An additional positive effect of using PDMS films is the control of malaria mosquitoes.

Under the indoor laboratory conditions, a series of long-term (84 days) experimental study of the effect of ultra-thin films of the PDMS-100 and PDMS-200 polydimethylsiloxanes with a layer thickness of $1 \mu \mathrm{m}$ on the evaporation rate from the water free surface was conducted.

The dynamics of change in time of daily effect of evaporation retardation by means of PDMS films, and also total effect from the beginning of experiment are obtained. The maximum daily effects of evaporation reduction were obtained on the 6th day of the study; they are equal to $39.5 \%$ for the PDMS-200 film and 32.9\% for the PDMS100 film, respectively. After almost complete cessation of the effect at 5th week, starting from 39th day, the reduction of evaporation in the tanks with PDMS films was steadily restored, but at different levels. Thus, in the tank \#2 with the PDMS200 film, the daily effect varied in the range from $6.4 \%$ to $30.9 \%$, while the daily efficiency of the PDMS-100 film did not exceed $10.5 \%$.

Time dependence of the total effect of reducing water evaporation during the first 5 weeks of the study was similar for both films with a maximum total effect of $28.4 \%$ for the first 7 days for PDMS-200 and 23.3\% for the first 9 days for PDMS-100. Overall integral efficiency of evaporation retardation by the PDMS-200 film with a thickness of $1 \mu \mathrm{m}$ for 84 days was equal to $17.2 \%$, while for the PDMS-100 film of the same thickness only $5.7 \%$.

Linear correlations (4) - (6) are obtained between the values of the mass transfer 
coefficient and the free surface temperature for water without additives, as well as for similar tanks with ultra-thin PDMS films with a thickness of $1 \mu \mathrm{m}$. Due to the long-term evaporation retardation effect, ultra-thin films of polydimethylsiloxanes, especially of PDMS-200 can be a profitable alternative to the use of monolayers based on fatty alcohols.

\section{REFERENCES}

1. Bukhari T., Takken W., Githeko A.K., Koenraadt C.J.M. 2011. Efficacy of Aquatain, a monomolecular film, for the control of malaria vectors in rice paddies. PLoS ONE, 6 (6), e21713.

2. Chigrinets A., Mazur L. Duskayev K., Chigrinets L., Akhmetova S. 2019. Water economy balance of the Almaty City. Journal of Ecological Engineering, 20(3), 194-203.

3. Craig I., Green A., Scobie M., Schmidt E. 2005. Controlling evaporation loss from water storages. National Centre for Engineering in Agriculture University of Southern Queensland, Toowoomba, 207.

4. Eduok U., Faye O., Szpunar J. 2017. Recent developments and applications of protective silicone coatings: A review of PDMS functional materials. Progress in Organic Coatings, 111, 124-163.

5. Fendinger N.J., McAvoy D.C., Eckhoff W.S., Price B.B. 1997. Environmental occurrence of polydimethylsiloxane. Environmental Science \& Technology, 31(5), 1555-1563.

6. Gallego-Elvira B., Martínez-Alvarez V., Pittaway P., Brink G., Martín-Gorriz B. 2013. Impact of micrometeorological conditions on the efficiency of artificial monolayers in reducing evaporation. Water Resource Management, 27, 2251-2266.

7. Graiver D., Farminer K.W., Narayan R.A. 2003. Review of the fate and effects of silicones in the environment. Journal of Polymers and the Environment, 11, 129-136.

8. Gorjizade A., Akhondali A.M., Zarei H., Kaboli H.S. 2014. Evaluation of eight evaporation estimation methods in a semi-arid region (Dez reservoir, Iran). International Journal of Advanced Biological and Biomedical Research, 2(5), 1823-1836.

9. Griessbach E.F.C., Lehmann R.G. 1999. Degradation of polydimethylsiloxane fluids in the environment - a review. Chemosphere, 38(6), 1461-1468.

10. Gugliotti M., Baptista M.S., Politi M.J. 2005. Reduction of evaporation of natural water samples by monomolecular films. Journal of the Brazilian Chemical Society, 16(6A), 1186-1190.

11. Information and Analytical Report on the State of Water Resources of the Ukraine and Features of Agricultural Production in the Conditions of Climate Change. 2020. National Academy of Agrarian Sciences of Ukraine. http://naas.gov. ua/upload/iblock/78a/Інформаційна довідка 4.05.2020-конвертирован.pdf (in Ukraine)

12. Liu J.P., Li L., Miao C.W., Tian Q., Ran Q.P., Wang Y.J. 2011. Reduction of water evaporation and cracks on plastic concrete surface by monolayers. Colloids and Surfaces A: Physicochemical and Engineering Aspects, 384(1-3), 496-500.

13. Mojsiewicz-Pieńkowska K. 2015. Review of current pharmaceutical applications of polysiloxanes (silicones). [In:] V.K. Thakur, M.K. Thakur (Ed.): Handbook of Polymers for Pharmaceutical Technologies: Processing and Applications. Scrivener Publishing LLC, 2, 363-381. doi. org/10.1002/9781119041412.ch13

14. Mozafari A., Mansouri B., Chini S.F. 2019. Effect of wind flow and solar radiation on functionality of water evaporation suppression monolayers. Water Resource Management, 33, 3513-3522.

15. Panjabi K., Rudra R., Goel P. 2016. Evaporation retardation by monomolecular layers: An experimental study at the Aji reservoir (India). Open Journal of Civil Engineering, 6, 346-357.

16. Retardation of Evaporation by Monolayers: Transport Processes. 1962. Ed. V.K. La Mer. Academic Press, New York, 277.

17. Rudakov L.M., Hapich H.V., Chushkina I.V. 2017. Evaporation from the water surface of the control pools of irrigation systems. Scientific Bulletin of DSAEU, 2(44), 74-77 (in Ukraine) https://dspace. dsau.dp.ua/jspui/bitstream/123456789/1441/1/1.pdf

18. Saggaï S., Bachi O.E.K. 2018. Evaporation reduction from water reservoirs in arid lands using monolayers: Algerian experience. Water Resources Development: Economic and Legal Aspects, 45, 280-288.

19. Shilo E., Ziv B., Shamir V., Rimmer A. 2015. Evaporation from Lake Kinneret, Israel, during hot summer days. Journal of Hydrology, 528, 264-275.

20. Weiss O., Scharf B., Pitha U. 2019. Evapotranspiration of technical substrates - methodology for calculating evapotranspiration of technical substrates. Journal of Ecological Engineering, 20(9), 28-37.

21. Zhuk V., Hrytsiv O., Rehush A. 2020. Retardation of water losses on evaporation by means of a layer of polydimethylsiloxane. Journal of Lviv National Agrarian University. Architecture and Farm Building, 21, 56-60. https://doi.org/10.31734/architecture2020.21.056 (in Ukrainian).

22. Zhuk V., Vovk L., Matlai I., Popadiuk I. 2021. Maximum daily stormwater runoff flow rates at the inlet of the Lviv WWTP based on the results of systematic hydrologic observations of the catchment. Lecture Notes in Civil Engineering, 100, 514-521. 